SANTOS, O.S. et al. Forrageiras hidropônicas de triticales com ervilhaca peluda. PUBVET, Londrina, V. 6, N. 7, Ed. 194, Art. 1303, 2012.

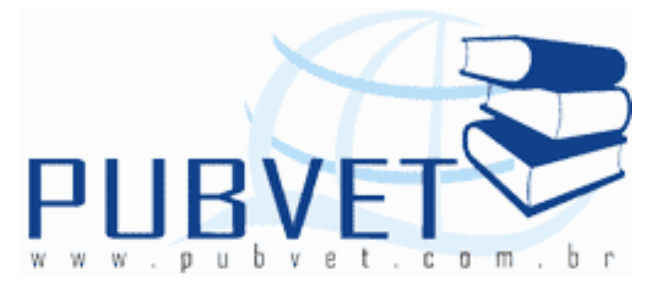

PUBVET, Publicações em Medicina Veterinária e Zootecnia.

\title{
Forrageiras hidropônicas de triticales com ervilhaca peluda
}

\section{Osmar Souza dos Santos ${ }^{1}$, Alfredo do Nascimento Junior ${ }^{2}$, Denise Puntel} Basso $^{3}$, Alberto Cargnelutti Filho ${ }^{4}$, Jorge Eugênio Filipetto ${ }^{5}$, Rodrigo da Costa Luz $^{6}$, Francisco Roberto Souilljee ${ }^{7}$

${ }^{1}$ Engenheiro Agrônomo, Doutor, Professor Colaborador do Colégio Politécnico da Universidade Federal de Santa Maria (UFSM). Pesquisador do CNPq. 97105900, Santa Maria, RS. osmarsouzasantos@gmail.com

2 Engenheiro Agrônomo, Doutor, Pesquisador da Embrapa-Trigo. 99001-970, Passo Fundo, RS. alfredo@cnpt.embrapa.br

${ }^{3}$ Engenheira Agrônoma da UFSM. denisepbasso@gmail.com

${ }^{4}$ Engenheiro Agrônomo, Doutor, Professor do Departamento de Fitotecnia da UFSM. cargnelutti@ufrgs.br

${ }^{5}$ Técnico do Colégio Politécnico da UFSM. jorgefilipetto@gmail.com

${ }^{6}$ Acadêmico da UFSM. rodrigodacostaluz@yahoo.com.br

${ }^{7}$ Engenheiro Agrônomo, Sementes Souilljee, Carazinho, RS.

\section{Resumo}

O experimento foi executado no Colégio Politécnico da Universidade Federal de Santa Maria (UFSM) - RS, com objetivo de avaliar a produção de forrageiras hidropônicas de três variedades de triticale (X Triticosecale Wittmack): BRS Saturno, BRS Ulisses e Embrapa 53, nas densidades de 2,0 $\mathrm{kg} \mathrm{m}^{-2}$, associadas com quatro densidades da cultivar ervilhaca peluda SS Esmeralda (Vicia villosa 
SANTOS, O.S. et al. Forrageiras hidropônicas de triticales com ervilhaca peluda. PUBVET, Londrina, V. 6, N. 7, Ed. 194, Art. 1303, 2012.

Roth) nas doses de $0,150,300$ e $450 \mathrm{~g} \mathrm{~m}^{-2}$, no período do inverno de 2011 . 0 experimento foi conduzido em túnel alto com cada tratamento em área de 1,0 $\mathrm{m}^{-2}$, utilizando-se solução nutritiva descrita por Santos et al. (2004). As avaliações foram realizadas aos 20 dias após a semeadura. A variedade BRS Saturno apresentou a máxima produtividade média, $15,500 \mathrm{~kg} \mathrm{~m}^{-2}$, seguida da Embrapa 53 com 12,973 $\mathrm{kg} \mathrm{m}^{-2}$ e da BRS Ulisses com 12,117 kg m${ }^{-2}$. Ocorreu aumento da massa verde total em função do aumento das doses de ervilhaca peluda.

Palavras-chave: hidroponia, forrageiras, triticales, SS Ametista.

\section{Production of hydroponic fodder of triticale with common vetch}

\section{Abstract}

An experiment was conducted at the Colégio Politécnico da Universidade Federal de Santa Maria (UFSM) - RS, in order to evaluate the production of hydroponic fodder of three varieties of triticale (X Triticosecale Wittmack): BRS Saturno, BRS Ulisses and Embrapa 53 at the densities $2.0 \mathrm{~kg} \mathrm{~m}^{-2}$, associated with four densities of hairy vetch SS Ametista (Vicia villosa Roth.) at doses of $0,150,300$ and $450 \mathrm{~g} \mathrm{~m}^{-2}$, during the winter of 2011. The experiment was conducted in a high tunnel with each treatment in an area of $1.0 \mathrm{~m}^{-2}$, using a nutrient solution described by Santos et al. (2004). Evaluations were performed at 20 days after sowing. BRS Saturno had the highest average yield with $15.50 \mathrm{~kg} \mathrm{~m}^{-2}$ followed by Embrapa 53 with $12.97 \mathrm{~kg} \mathrm{~m}^{-2}$ and BRS Ulisses with $12.12 \mathrm{~kg} \mathrm{~m}^{-2}$. Vetch dosis increased the total dry matter linearly.

Keywords: hydroponics, forage, triticales, hairy vetch, SS Ametista.

\section{INTRODUÇÃO}

No sul do Brasil ocorre deficiência nas pastagens, no inverno por causa das baixas temperaturas, geadas e excessos de chuvas, e no verão por causa da falta de chuvas adequadas. 
SANTOS, O.S. et al. Forrageiras hidropônicas de triticales com ervilhaca peluda. PUBVET, Londrina, V. 6, N. 7, Ed. 194, Art. 1303, 2012.

Para suprir a deficiência das pastagens naturais indica-se a produção de pastagens realizadas na hidroponia. O cultivo de forragem hidropônica é uma tecnologia de produção de biomassa vegetal obtida através da germinação e desenvolvimento inicial das plantas a partir de sementes viáveis, de alta digestibilidade e qualidade nutricional (FAO, 2001).

A produção das forrageiras hidropônicas tem como vantagens a eliminação do uso de defensivos agrícolas, uma vez que não ocorrem invasoras prejudiciais, doenças e pragas no sistema, ciclo de produção mais rápido, independência das mudanças nas condições climáticas ao longo do ano, maior produtividade por unidade de área, redução da mão de obra, redução das tarefas inerentes à produção e conservação de forragens (silagem, fenação), economia e melhor aproveitamento dos fertilizantes, liberação de área para uso com outras culturas e uso de diferentes espécies vegetais (SANTOS et al., 2002).

A utilização de forragem hidropônica de alta qualidade, obtida em condições de ambientes protegidos, permite ao produtor manter e aumentar a produtividade de seus rebanhos independente das variações climáticas, resultando em maior estabilidade da produção.

Entre as várias espécies vegetais que podem ser utilizadas para produção de forragens hidropônicas cabe destaque as cultivares de triticale, que vêm sendo pesquisadas (SANTOS et al., 2010).

O triticale é cereal abundantemente encontrado no sul do Brasil, tem na alimentação animal sua principal utilização, com o uso de grãos na forma de ração para suínos e aves (NASCIMENTO JUNIOR et al., 2004).

Por sua vez, as ervilhacas podem também contribuir na qualidade da forragem hidropônica assim como nos diferentes sistemas de cultivo para cobertura de solo e para pastejo animal.

Esta pesquisa teve como objetivo avaliar a produção de três cultivares de triticale em hidroponia associadas com quatro densidades de Ervilhaca Peluda. 
SANTOS, O.S. et al. Forrageiras hidropônicas de triticales com ervilhaca peluda. PUBVET, Londrina, V. 6, N. 7, Ed. 194, Art. 1303, 2012.

\section{MATERIAL E MÉTODOS}

O experimento foi realizado no Colégio Politécnico da Universidade Federal de Santa Maria - RS, com coordenadas geográficas: latitude 29042'S, longitude $53^{\circ} 43^{\prime} \mathrm{W}$ e altitude $95 \mathrm{~m}$.

As variedades foram conduzidas em um túnel alto com $6 \mathrm{~m}$ de largura e $30 \mathrm{~m}$ de comprimento, disposto no sentido norte-sul, coberto com polietileno de baixa densidade (PEBD) com espessura de $150 \mu$, aditivado contra raio ultravioleta. Os canteiros foram confeccionados com filme plástico (lona preta de $100 \mu$ de espessura), estendidos sobre o solo nivelado, sendo as bordas limitadas por guias de madeira com $6,0 \mathrm{~cm}$ de altura, formando parcelas de $1,0 \mathrm{~m}^{2}$.

Antes da semeadura, foi realizada a técnica de pré-germinação que consistiu na embebição das sementes em água por 24 horas (SANTOS et al., 2006). Logo após, foram semeadas de acordo com cada tratamento.

As semeaduras foram realizadas no dia 17 de agosto e a colheita no dia 08 de setembro de 2011, com um período de 20 dias.

Foram utilizadas três cultivares de triticale (X Triticosecale Wittmack): BRS Saturno, BRS Ulisses e Embrapa 53, na densidade de 2,0 $\mathrm{kg} \mathrm{m}^{-2}$, associadas com ervilhaca peluda SS Esmeralda (Vicia villosa Roth) nas doses de $0,150,300$ e $450 \mathrm{~g} \mathrm{~m}^{-2}$ (Figuras 1 e 2).

As plantas receberam solução nutritiva especial para produção de forrageiras (SANTOS et al., 2004).

Aos 20 dias da semeadura foi feita a coleta e pesagem de quatro amostras de $0,20 \times 0,20 \mathrm{~m}$ de todos os tratamentos. 
SANTOS, O.S. et al. Forrageiras hidropônicas de triticales com ervilhaca peluda. PUBVET, Londrina, V. 6, N. 7, Ed. 194, Art. 1303, 2012.

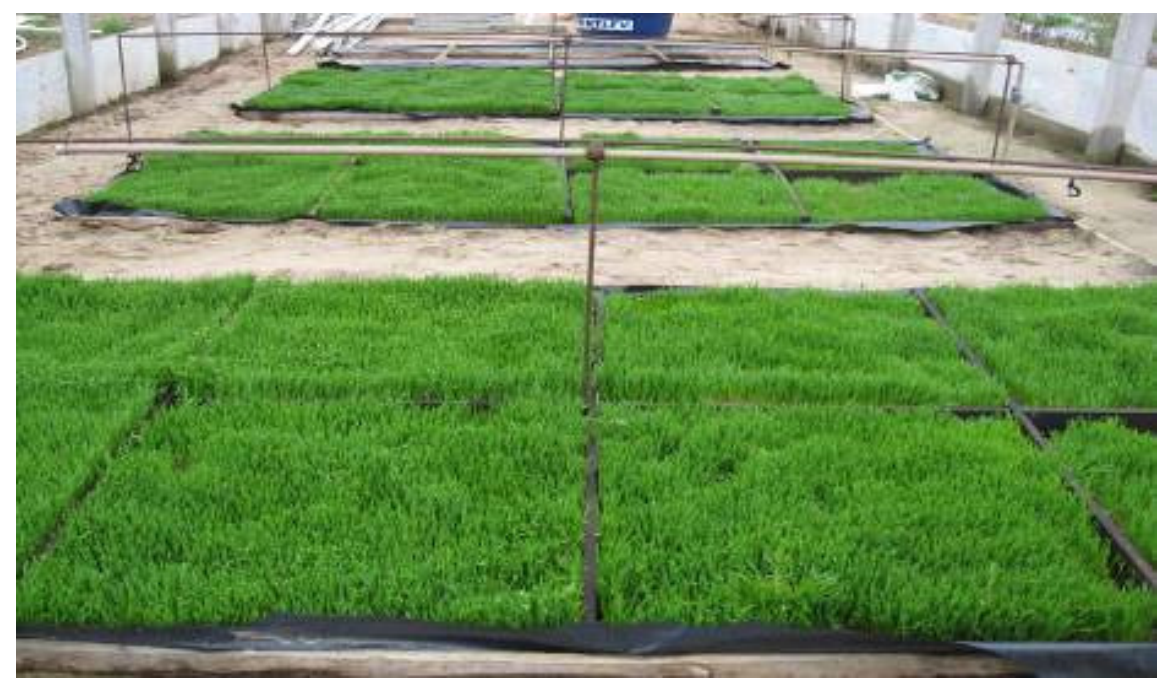

Figura 1. Fase de crescimento de triticales sem e com ervilhaca peluda SS Esmeralda.

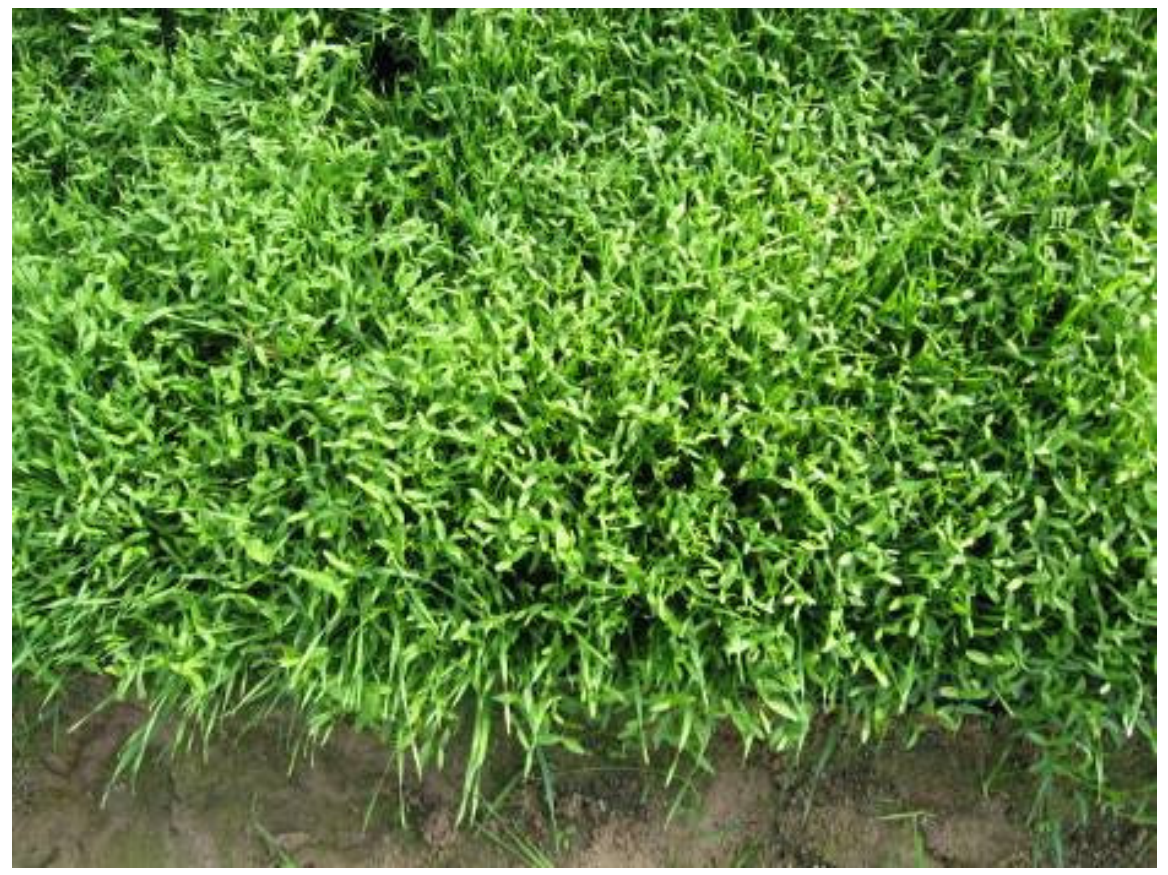

Figura 2. Produção de triticale com ervilhaca peluda SS Esmeralda. 
SANTOS, O.S. et al. Forrageiras hidropônicas de triticales com ervilhaca peluda. PUBVET, Londrina, V. 6, N. 7, Ed. 194, Art. 1303, 2012.

\section{RESULTADOS E DISCUSSÃO}

Os resultados obtidos nas pesagens, em $\mathrm{g} \mathrm{m}^{-2}$, foram transformados em $\mathrm{kg} \mathrm{m}^{-2}$ e kg ha-1.

A avaliação das doses de ervilhaca peluda demonstrou que houve reação positiva no aumento de $0,150,300$ e $450 \mathrm{~g} \mathrm{~m}^{-2}$ (Figura 3).

A maior produção, na média, foi da cultivar BRS Saturno com 15,500 kg $\mathrm{m}^{-2}$, equivalente a $155 \mathrm{t} \mathrm{ha}^{-1}$, seguida pela Embrapa 53, com 12,973 $\mathrm{kg} \mathrm{m}^{-2}$, equivalente a $129 \mathrm{t} \mathrm{ha}^{-1}$, tendo como última a BRS Ulisses com 12,117 $\mathrm{kg} \mathrm{m}^{-2}$, equivalente a $121 \mathrm{t} \mathrm{ha}^{-1}$ (Figura 4).

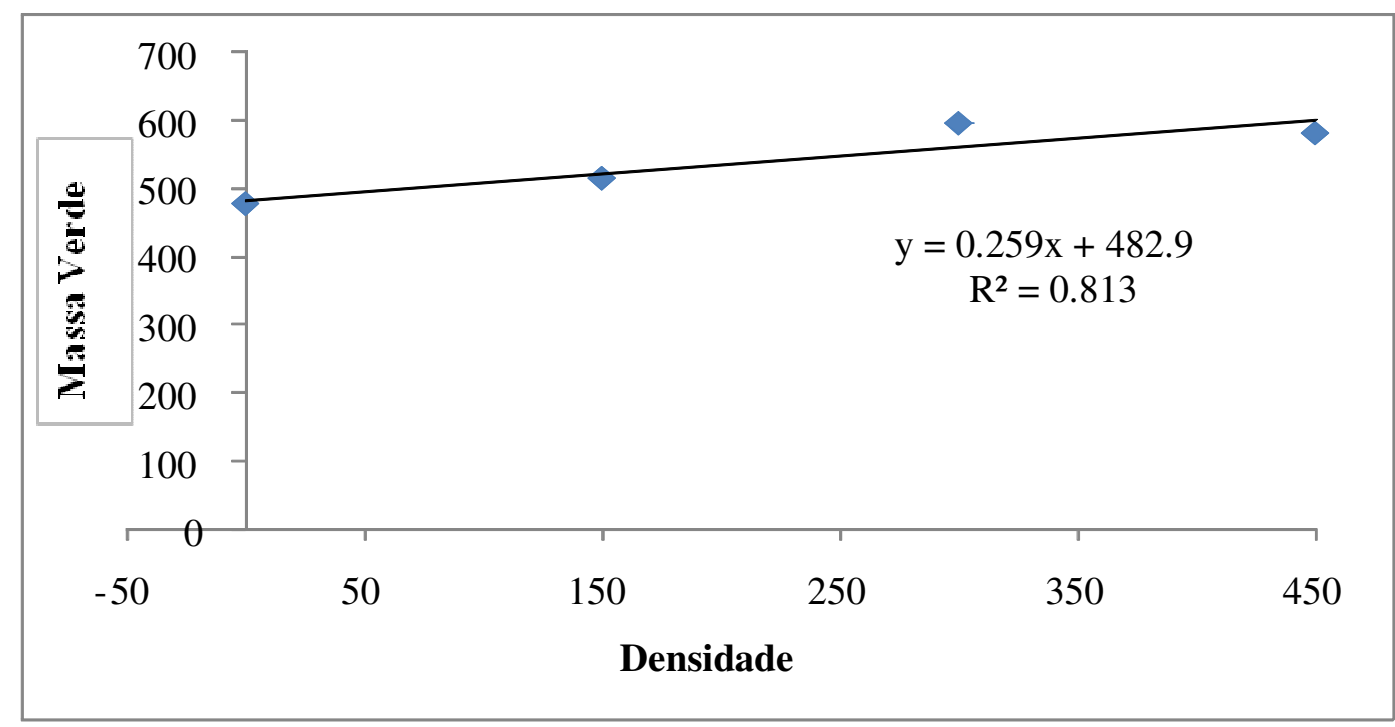

Figura 3. Aumento da massa verde $\left(\mathrm{g} \mathrm{m}^{-2}\right)$ em função do aumento das doses de ervilhaca peluda. 
SANTOS, O.S. et al. Forrageiras hidropônicas de triticales com ervilhaca peluda. PUBVET, Londrina, V. 6, N. 7, Ed. 194, Art. 1303, 2012.

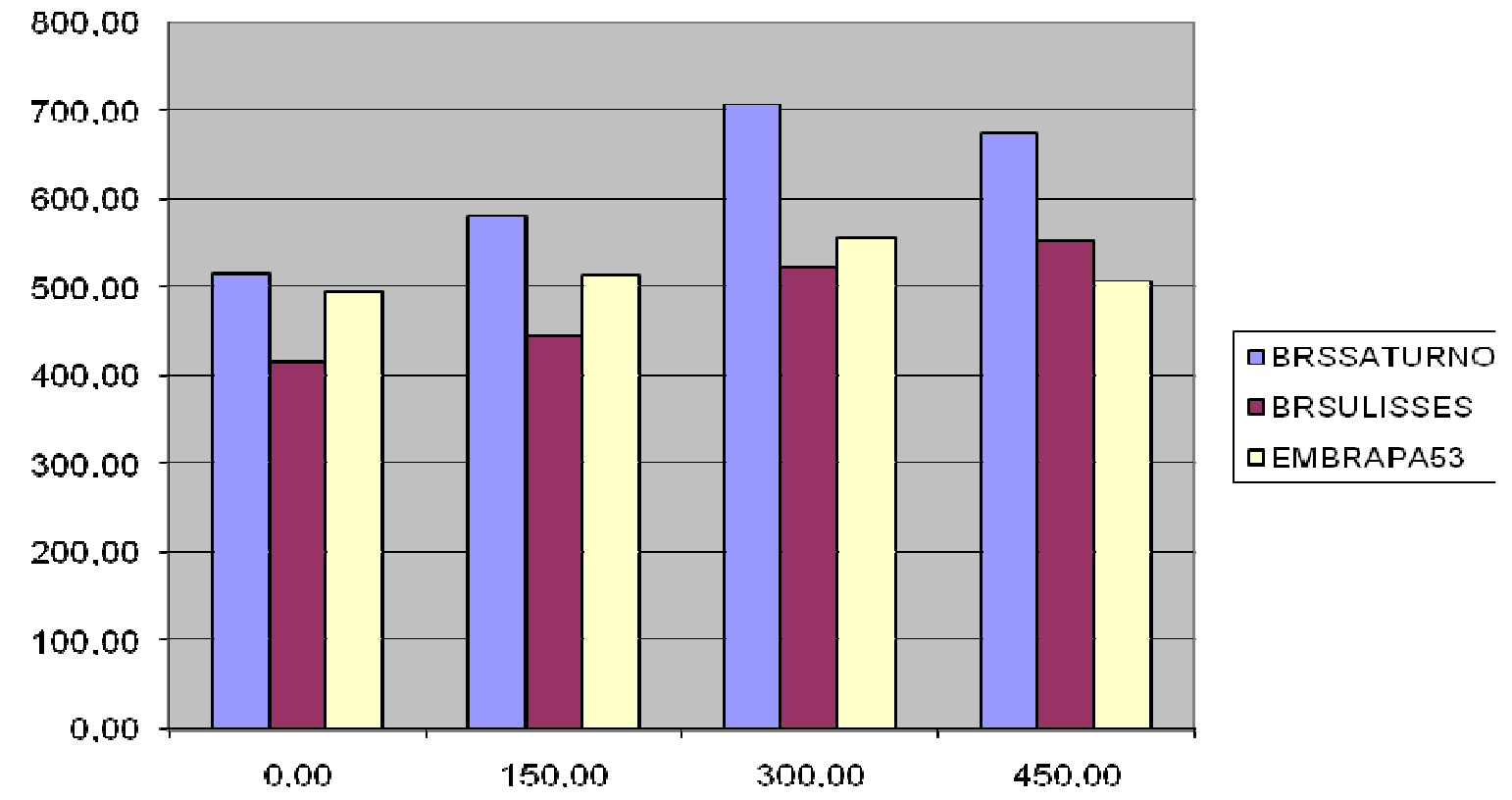

Figura 4. Produção da média de massa verde $\left(\mathrm{g} \mathrm{m}^{-2}\right)$ das amostras $(20 \times 20$ $\mathrm{cm})$ de três forrageiras de triticales $\left(2 \mathrm{~kg} \mathrm{~m}^{-2}\right)$ sem e com ervilhaca peluda ( 0 , 150,300 e $450 \mathrm{~g} \mathrm{~m}^{-2}$ ).

Os resultados obtidos destacaram como mais produtiva a BRS Saturno, seguida da Embrapa 53 e da BRS Ulisses. Verifica-se que houve redução na produção de forrageiras em comparação com outra pesquisa onde os valores foram $181 \mathrm{t} \mathrm{ha}^{-1}$ com a BRS Saturno, $209 \mathrm{t} \mathrm{ha}^{-1}$ com a Embrapa 53 e $223 \mathrm{t} \mathrm{ha}^{-1}$ com a BRS Ulisses, associadas com ervilhaca lisa (SANTOS et al., 2011).

\section{CONCLUSÕES}

A cultivar de triticale BRS Saturno, com $2 \mathrm{~kg} \mathrm{~m}^{-2}$, associada à ervilhaca peluda, com $300 \mathrm{~g} \mathrm{~m}^{-2}$, é mais produtiva, seguida da Embrapa 53 e da BRS Ulisses que são equivalentes entre si.

As doses mais eficientes de ervilhaca peluda são as de 300 e $450 \mathrm{~g} \mathrm{~m}^{-2}$ em associação com cultivares de triticale. 


\section{REFERÊNCIAS BIBLIOGRÁFICAS}

FAO. Manual técnico forraje verde hidropônico. Santiago, 2001. v.1, 73p.

FONTANELI, R.S.; SANTOS, H.P.; BAIER, A.C. Leguminosas anuais de inverno. In: FONTANELI, R.S. et al. Forrageiras para integração lavoura-pecuária-floresta na região SulBrasileira. Passo Fundo: Embrapa, 2009, p.247-262.

NASCIMENTO JUNIOR, A.; BAIER, A.C.; TEIXEIRA, M.C.C.; WIETHÖLTER, S. Triticale in Brazil. In: Mohamed Mergoum; Helena Gómez MacPherson. (Org.). Triticale Improvement And Production. 1 ed. Roma: FAO, 2004, v.1, p.93-98.

SANTOS, O.S.; MANFRON, P.A.; MÜLLER, L.; MEDEIROS, S.L.P.; TONETTO, C.J.; BANDEIRA, A.H.; DUARTE, T.S.; LUZ, G.L.; BORCIONI, E. Produção e qualidade nutricional da forragem hidropônica. Informe Técnico. Santa Maria: UFSM/CCR, 2006, 8p. (34/2006).

SANTOS, O.S.; NASCIMENTO JUNIOR, A.; BASSO, D.P.; CARGNELUTTI FILHO, A.; FILIPETTO, J.E.; LUZ, R.C.; ROCHA, V. Produção de forrageiras hidropônicas de triticales com ervilhaca comum. PUBVET, Londrina, v.5, n.38, ed. 185, art. 1248, 2011. 8p.

SANTOS, O.S.; MÜLLER, L.; PIRES, C.; TONETTO, C.J.; MEDEIROS, S.L.P.; FRESCURA, R.B.N. ; HAUT, V.; SILVA, D.V.R. Produção de forragem hidropônica de cevada e milho e seu uso na alimentação de cordeiros. Informe Técnico. Santa Maria: UFSM/CCR, 2004, 8p. (04/2004).

SANTOS, O.S.; NASCIMENTO JUNIOR, A.; FRONZA, D.; NOGUEIRA FILHO, H. et al. Produção de forrageiras hidropônicas de três espécies de poáceas, no inverno. PUBVET, Londrina, v.4, n.16, ed. 121, art. 821, 2010.

SANTOS, O.S.; SCHMIDT, D.; NOGUEIRA FILHO, H.; LONDERO, F.A. Produção de forragem hidropônica. In:__. Cultivos sem solo: hidroponia. 2a. Reimpressão. Santa Maria: UFSM/CCR, 2002, p.94-98. (Caderno Didático, 01). 